\title{
Simultaneous detection of cow and buffalo species in milk from China, India, and Pakistan using multiplex real-time PCR
}

\author{
G. Cottenet, ${ }^{1}$ C. Blancpain, and P.-A. Golay \\ Quality and Safety Department, Nestlé Research Center, PO Box 44, 1000 Lausanne 26, Switzerland
}

\begin{abstract}
Asian countries are major producers of cow and buffalo milk. For quality and authenticity purposes, a multiplex real-time PCR assay was developed to specifically and simultaneously detect DNA from these 2 bovine species. Targeting the cytochrome $b$ gene of mitochondrial DNA, common PCR primers amplified a 105-bp fragment, and 2 fluorescent probes specific to either cow or buffalo were designed for their identification. Specificity was successfully tested on 6 other species, including sheep and goat, and sensitivity reached $1 \%$ of cow DNA in buffalo DNA and vice versa. As an evaluation, the method was tested using 119 freezedried Asian milk samples from regional industrial milk facilities. Although these samples did not cover the entire Asian zone, the multiplex assay indicated that approximately $20 \%$ of the samples (mainly from India) showed high levels of cross-contamination of cow milk by buffalo milk, and vice versa. Fast, sensitive, and straightforward, this method is fit-for-purpose for the authenticity control of Asian milk.
\end{abstract}

Key words: cow milk, buffalo milk, multiplex, realtime polymerase chain reaction

\section{INTRODUCTION}

Animal species authentication in food products plays a major role in traceability, quality, and safety purposes. Species substitution or cross-contamination can indeed lead to regulatory noncompliance, religious concerns, or allergic issues. Dairy products are included in these concerns, particularly with respect to the adulteration of Mozzarella cheese with cow milk (López-Calleja et al., 2005) or milk fat adulteration with foreign fat (Molkentin, 2007). The applicability of the recent official standard ISO 17678 (ISO, 2010), which was validated on mainly European cow milk samples, for foreign fat detection in cow milk fat needs to be evaluated on Asian milk. For this purpose, a

Received January 20, 2011.

Accepted April 23, 2011.

${ }^{1}$ Corresponding author: geoffrey.cottenet@rdls.nestle.com survey was initiated to establish triacylglycerol profiles on samples collected at milk collection centers in Asia. However, the purity of Asian cow milk, with respect to contamination with buffalo milk, is questionable, knowing that India, Pakistan, and China are recognized as the 3 main producers of cow and buffalo milks in Asia according to the Food and Agriculture Organization of United Nations (FAOSTAT, 2010).

To ensure product authenticity and traceability and avoid possible species mixture and fraud, many methods have been developed, such as 2-dimensional electrophoresis (Chianese et al., 1990), isoelectric focusing (Moio et al., 1990), capillary electrophoresis (Recio et al., 2004), HPLC (Mayer et al., 1997; Mayer, 2005), ELISA (Asensio et al., 2008), and chromatographic techniques (Chou et al., 2007). However, these techniques are often limited when assaying heat-treated or processed products. To overcome these difficulties, the use of DNA-based methods and especially PCR techniques are of great interest compared with proteinbased methods (Pascoal et al., 2005).

The majority of PCR-based animal authentication methods focus on mitochondrial DNA sequences. Because of its high conservation within individual species and its high copy number in animal cells, the cytochrome $b$ gene is regularly targeted, thus increasing the specificity and sensitivity of the assay (Fajardo et al., 2010). Milk is furthermore known as a valuable source of DNA to discriminate animal species by PCR due to the presence of somatic cells (Lipkin et al., 1993).

Cow and buffalo detection have already been studied, especially for traceability and authenticity in Mozzarella cheese (López-Calleja et al., 2005; Lopparelli et al., 2007). However, because cow contamination was suspected and targeted, PCR methods have often been developed for cow detection only. Many of these DNA-based methods developed for authentication purpose rely on PCR-RFLP (Mafra et al., 2008), which can lead to problems in interpretation of results due to incomplete DNA digestion (Quinteiro et al., 1998), and the need to handle post-PCR products significantly increasing the risk of laboratory contamination. Recently, classical PCR methods evolved to real-time PCR (RT-PCR) enabling detection of cow and buf- 
falo in the same reaction based on allelic discrimination (Dalmasso et al., 2011).

The purpose of this study was to develop a new multiplex RT-PCR targeting the cytochrome $b$ gene to detect cow and buffalo species simultaneously. Although not covering the whole Asian zone, the new assay was tested on Asian milk samples from regional industrial milk facilities located in India, China, and Pakistan to evaluate potential mixtures and contaminations.

\section{MATERIALS AND METHODS}

\section{DNA References and Milk Samples}

Certified DNA references from cow (Bos taurus), buffalo (Bubalus bubalis), goat (Capra hircus), sheep (Ovis aries), horse (Equus caballus), pig (Sus scrofa), chicken (Gallus gallus), and turkey (Meleagris gallopavo) were purchased at Coring Systems Diagnostix (Gernsheim, Germany) and supplied lyophilized. Once reconstituted at $20 \mathrm{ng} / \mu \mathrm{L}$ in elution buffer $(10 \mathrm{~m} M$ Tris- $\mathrm{HCl}, \mathrm{pH}$ 8.5; Qiagen, Hilden, Germany), DNA solutions were stored at $-20^{\circ} \mathrm{C}$.

In total, 119 Asian milk samples, 80 labeled as cow milks and 39 labeled as buffalo milks, were collected at milk collection centers in China, India, and Pakistan (respectively 40, 20, and 20 cow milk samples; 0, 20, and 19 buffalo milk samples). Collected from tankers of 200 to $8,000 \mathrm{~L}, 100 \mathrm{~mL}$ of each milk sample was freezedried with the Freeze Dryer Alpha1-4LDPlus (Martin Christ Gefriertrocknungsanlagen GmbH, Osterode am Harz, Germany), and the residual powder was then stored at $-20^{\circ} \mathrm{C}$.

\section{DNA Extraction}

DNA from lyophilized milk samples was extracted with a hexadecyltrimethylammonium bromide (CTAB)-based protocol, adapted for dairy products (Pirondini et al., 2010). One hundred milligrams of each milk powder were incubated in $1.5 \mathrm{~mL}$ of CTAB extraction buffer [1.4 M NaCl, $20 \mathrm{~m} M$ EDTA, $100 \mathrm{mM}$ Tris-HCl, 2\% (wt/vol) CTAB, pH 8.0] and $450 \mu \mathrm{g} /$ $\mathrm{mL}$ protease (Qiagen) at $65^{\circ} \mathrm{C}$ for $1 \mathrm{~h}$. After maceration, the samples were centrifuged at $15,000 \times g$ for $10 \mathrm{~min}$. The aqueous phase was transferred into a new tube, extracted with an equal volume of chloroform, and centrifuged again at $15,000 \times g$ for $10 \mathrm{~min}$. The supernatant was added to 5 volumes of PB binding buffer (Qiagen), mixed, and loaded onto a QIAquick column (Qiagen) over a vacuum manifold. The column was washed twice with $750 \mu \mathrm{L}$ of PE buffer (Qiagen), and the sample was dried at $12,000 \times g$ for 5 min and placed in a new centrifuge tube. The purified DNA was eluted by centrifugation for 5 min at $12,000 \times g$ with 50 $\mu \mathrm{L}$ of elution buffer (Qiagen) after 20 min of incubation and stored at $-20^{\circ} \mathrm{C}$.

\section{Primer and Probe Design}

The cytochrome $b$ sequences from Bos taurus and Bubalus bubalis were obtained from the GenBank database (GenBank accession nos. NC006853 and NC006295, respectively). Aligned with Megalign software (Lasergene DNASTAR, Madison, WI), the RT-PCR primers and probes were designed with Primer Express 3.0 software (Applied Biosystems, Foster City, CA).

A common pair of primers (BOVCytb-f: 5'-AATACACTACACATCCGACACAACAA- $3^{\prime}$ and BOVCytbr: 5'-GCTCCGTTTGCGTGTATGTATC-3') with $100 \%$ homology between cow and buffalo was designed, amplifying a 105-bp fragment. Two fluorescent TaqMan minor groove binder probes, using FAM (6-carboxyfluorescein) and VIC dyes, were designed on Bos taurus and Bubalus bubalis sequences, respectively (COW-p: 5'FAM-CTCTGTTACCCATATCTG-3' and BUFF-p: 5'VIC- CCTCCGTCGCCCACA-3').

\section{$R T-P C R$}

The RT-PCR amplifications were performed with the 7900HT Fast Real-Time PCR System (Applied Biosystems). All amplification reactions were carried out in a final volume of $50 \mu \mathrm{L}$ and contained $5 \mu \mathrm{L}$ of DNA (at a concentration of $20 \mathrm{ng} / \mu \mathrm{L}$ ), $1 \times$ TaqMan Universal PCR Mastermix (Applied Biosystems), 0.9 $\mu M$ of forward and reverse primers, and $0.1 \mu M$ of each probe. After $5 \mathrm{~min}$ at $50^{\circ} \mathrm{C}$ to activate the degradation of any potential carryover contamination by the uracyl- $\mathrm{N}$-glycosylase enzyme contained in the TaqMan PCR mastermix, the hot-start Taq DNA polymerase was activated for $10 \mathrm{~min}$ at $95^{\circ} \mathrm{C}$. The thermocycling conditions consisted of 40 cycles of a denaturation step of $15 \mathrm{~s}$ at $95^{\circ} \mathrm{C}$ and an annealing/elongation step of 1 min at $60^{\circ} \mathrm{C}$. Data analysis was performed with SDS software 2.3 (Applied Biosystems).

\section{Estimation of Cow and Buffalo Content}

Without the establishment of standard curves or the use of a bovine reference gene for $2^{-\Delta \Delta \mathrm{CT}}$ quantification, quantitative determination cannot be directly applied. However, cow and buffalo content in each sample can be estimated through direct relative quantitative PCR (drqPCR) described by Bernth Jensen et al. (2010), provided that the PCR efficiency has been shown equivalent for both species. For this purpose, PCR efficiencies were calculated and compared based on stan- 
dard curves prepared by serial dilution in water of cow or buffalo DNA references, from 100 to $0.01 \%$. Mixes of cow and buffalo DNA were also prepared from 100 to $10 \%$ to establish standard curves and to calculate PCR efficiencies when the 2 bovine species were present.

Considering that cow and buffalo milk contents represent $100 \%$ of each milk sample, cow or buffalo relative proportion $\mathrm{P}(\%)$ was expressed using the difference of cycle threshold $\left(\mathbf{C}_{\mathrm{T}}\right)$ value $\left(\Delta \mathrm{C}_{\mathrm{T}}\right)$ obtained for cow and buffalo amplifications during the RT-PCR:

$$
\mathrm{P}(\%)=\left(100-\frac{2^{\Delta C_{T}}}{1+2^{\Delta C_{T}}}\right) \times 100 .
$$

Percentages of cow or buffalo content were then sorted into 1 to 5,5 to 10,10 to 20 , and 20 to $50 \%$ cross-contamination ranges.

\section{RESULTS AND DISCUSSION}

\section{Multiplex RT-PCR Performance}

In the present study, a new multiplex RT-PCR was developed to simultaneously detect cow and buffalo mitochondrial DNA in milk samples. Presenting $87.5 \%$ of homology in their cytochrome $b$ sequences, a common primer pair was designed on a conserved region from cow and buffalo. Two fluorescent probes (FAM and VIC) were designed to differentiate cow and buffalo detection, expecting FAM amplification on cow DNA only, and VIC amplification on buffalo DNA only. Although known to be highly conserved, the cytochrome $b$ gene can present some polymorphisms that can affect species identification (Prado et al., 2007). To evaluate their location and frequency on the region targeted by the primers and probes, 212 and 153 cytochrome $b$

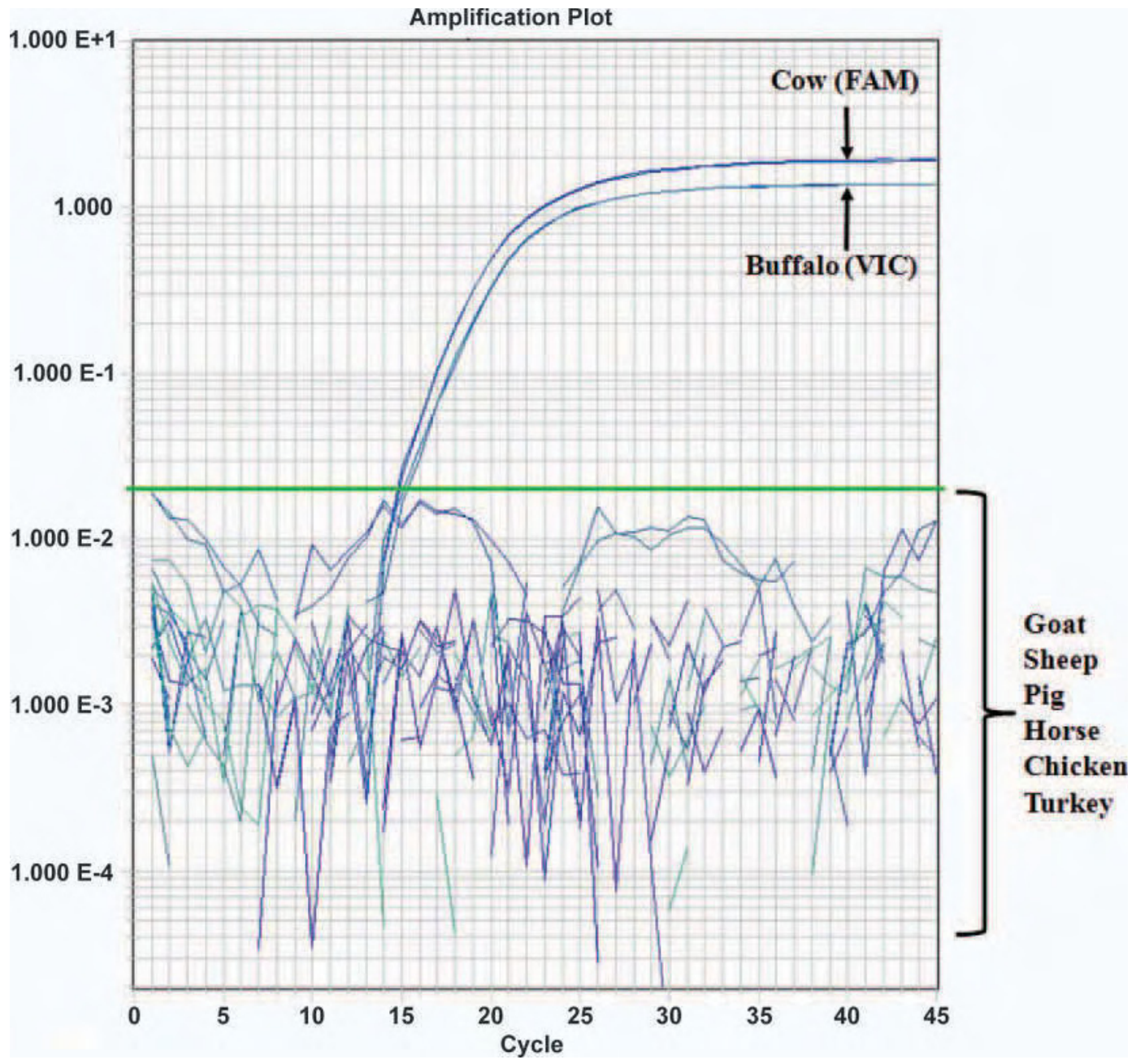

Figure 1. Amplification curves of the multiplex assay on cow, buffalo, goat, sheep, pig, horse, chicken, and turkey pure DNA; FAM and VIC detectors are linked to cow and buffalo detection, respectively. The plot displays the reporter dye (FAM or VIC) fluorescence signal in log scale (y-axis) as a function of run cycle (x-axis). Color version available in the online PDF. 
Table 1. Cow and buffalo PCR efficiencies based on standard curves prepared separately in water or prepared in a DNA mixture ${ }^{1,2}$

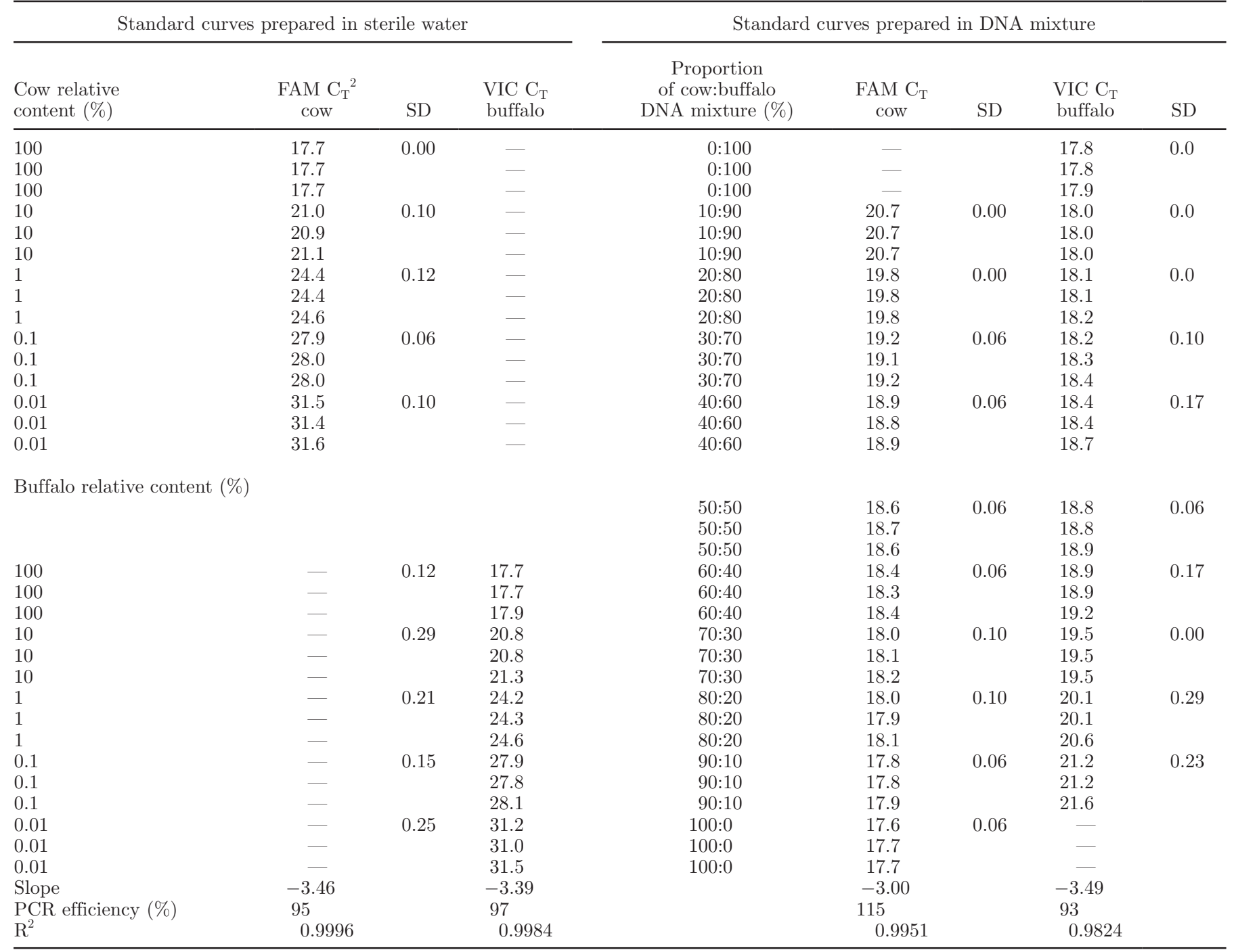

${ }^{1}$ Each standard point was assayed in triplicate; $\mathrm{SD}=$ standard deviation of triplicates.

${ }^{2} \mathrm{FAM}$ and $\mathrm{VIC}=$ fluorescent markers; $\mathrm{C}_{\mathrm{T}}=$ cycle threshold.

DNA sequences from Bos taurus and Bubalus bubalis, including Asian breeds, were retrieved from the GenBank database. Once aligned, no polymorphisms were observed on the DNA regions targeted by BOVCytb$\mathrm{r}$ primer and COW-p probe, whereas $1.8 \%$ of the cow sequences presented a SNP in the middle of the BOVCytb-f primer, and $7.8 \%$ of the buffalo sequences showed a SNP in the $5^{\prime}$ side of the BUFF-p probe. Not located on the $3^{\prime}$ extremities (Ghedira et al., 2009) and encountered at low frequencies, these polymorphisms were not considered critical or likely to reduce the efficiency of the assay.

Certified DNA references were tested in duplicate on this multiplex RT-PCR to evaluate the specificity of the method. The FAM and VIC signals successfully amplified on cow and buffalo, respectively, whereas no amplification occurred with DNA from goat, sheep, pig, horse, chicken, or turkey (Figure 1). No FAM signal was observed on buffalo DNA, and no VIC signal was detected on cow DNA, indicating the specificity of the designed assay.

To evaluate the sensitivity of the multiplex RT-PCR, mixtures of cow and buffalo reference DNA were prepared and tested. A buffalo content as low as $1 \%$ was detectable in cow DNA and vice versa. This low detection limit is due to the common primer pair that is shared by cow and buffalo DNA targets and consumed by the predominant species. Although quite low for RTPCR, which can reach detection limits of $0.01 \%$, this sensitivity is still appropriate for authenticity purposes.

To further estimate the buffalo or cow content in milk samples by drqPCR, according to Bernth Jen- 
sen et al. (2010), both cow and buffalo amplifications must be shown to be similar. Efficiencies of PCR were calculated and compared based on standard curves prepared by serial dilution in water of cow or buffalo DNA references, and by mixing cow and buffalo DNA. When diluted into water, cow and buffalo amplifications led to equivalent PCR efficiencies of 95 and $97 \%$, respectively, with coefficients of regression $R^{2}>0.99$ (Table 1). When diluting DNA of one into the other, PCR efficiencies were 115 and 93\%, respectively, with $\mathrm{R}^{2}>0.98$, which indicates excellent linearity. Such PCR efficiencies are indicative of absence of PCR inhibitions (Buh Gasparic et al., 2008) and considered comparable. Furthermore, a $100 \%$ cow DNA and a $100 \%$ buffalo DNA led to identical $\mathrm{C}_{\mathrm{T}}$ values close to 17.7 , and a mixture of 50:50\% cow:buffalo DNA lead to similar $\mathrm{C}_{\mathrm{T}}$ values close to 18.7 (Table 1). These data demonstrate that both cow and buffalo amplifications were similar during the multiplex RT-PCR, and that drqPCR could be applied to estimate cow and buffalo content.

\section{Analyses of Asian Milk Samples}

With the aim of evaluating the applicability of the recent ISO 17678 method (ISO, 2010) to Asian cow milk, purity and contamination with buffalo milk were estimated on samples obtained from Asian regional milk collection centers. Up to 8,000 L of milk from different farmers was collected and blended on site, thus reducing the potential effect on RT-PCR efficiency from the sequence polymorphisms observed previously.

Labeled as cow milk, 80 samples were extracted and analyzed with the newly designed assay. Cow was effectively detected in 79 samples, whereas one sample was certainly wrongly labeled because no cow was detected, only buffalo; this sample was not considered in the following interpretations. Buffalo was detected in $21 \%$ of these cow milk samples. Chinese milk did not show any buffalo contamination (Figure 2). Indian cow milk samples showed various amounts of buffalo content: $30 \%$ of these samples were not contaminated, and $20 \%$ presented a low buffalo content, $<5 \%$, considered as negligible. The other $50 \%$ presented a high buffalo content, between 5 and $50 \%$, considered as contamination. The majority of the cow milk samples from Pakistan were not contaminated with buffalo milk; however, approximately $10 \%$ of them showed a buffalo content between 10 and $20 \%$.

In addition to cow milk samples, 39 milk samples labeled as buffalo milks were collected from India and

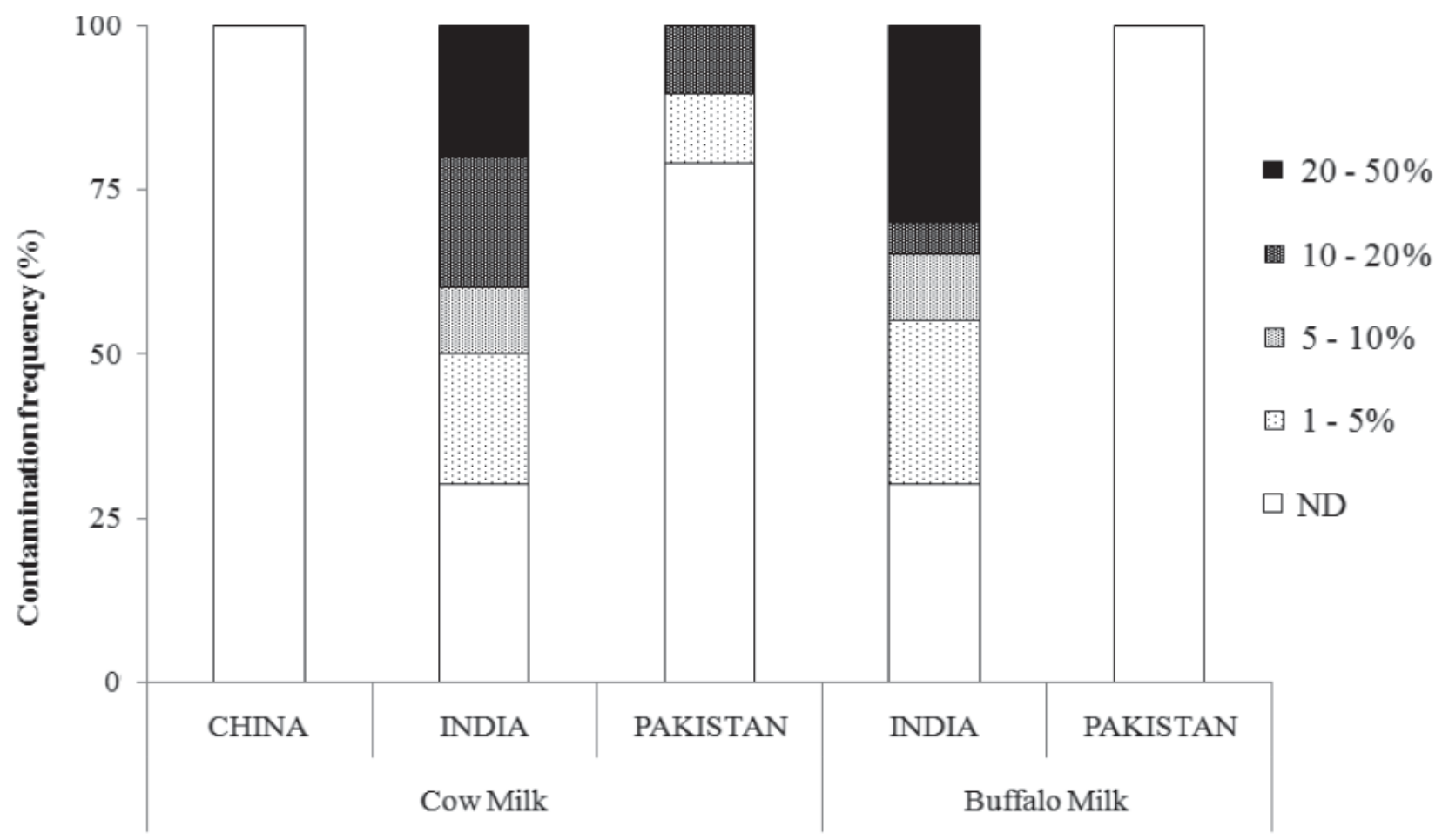

\section{Milk origin}

Figure 2. Buffalo contamination of cow milk from China $(\mathrm{n}=40)$, India $(\mathrm{n}=20)$, and Pakistan $(\mathrm{n}=19)$, and cow contamination of buffalo milk from India $(\mathrm{n}=20)$ and Pakistan $(\mathrm{n}=19)$. Levels of contamination were sorted in ranges of 1 to 5,5 to 10,10 to 20 , and 20 to $50 \%$. ND $=$ not detected. 
Pakistan only, China being a much lower producer of buffalo milk. Buffalo was detected in all these milks, whereas cow was detected in Indian samples only. Among them, 30\% were not contaminated, and 25\% contained a low amount of cow milk, $<5 \%$ (Figure 2 ). However, $45 \%$ of the Indian buffalo milk samples showed a higher cow contamination, from 5 to $50 \%$.

Cross-contamination between cow and buffalo milk occurred mainly on samples from India, which is known to be the most important producer of cow and buffalo milk worldwide (FAOSTAT, 2010). Although also reported as a major bovine milk producer, in this study, milk samples from Pakistan were cross-contaminated to a lesser degree.

In the present work, a multiplex RT-PCR assay able to identify specifically cow and buffalo with a detection limit of $1 \%$ was developed, by amplifying the cytochrome $b$ gene in mitochondrial DNA. The assay was shown to be specific against other animal species, and fast and sensitive enough for authenticity purposes. Tested on Asian milk samples labeled as either pure cow or pure buffalo milk, the method indicated significant cross-contamination of cow and buffalo milk in approximately $20 \%$ of the samples, mainly from India, at levels that can be considered adulteration. However, these samples did not cover the whole Asian zone, as they were collected at regional milk facilities in China, India, and Pakistan. As shown in this study, this method can be useful to demonstrate purity of cow or buffalo dairy products, either as a preliminary method before applying ISO 17678 (ISO, 2010) or for establishing authenticity of Mozzarella cheese.

\section{ACKNOWLEDGMENTS}

We thank Nestlé Shah Alam Regional Laboratory in Malaysia (Chooi Soo Hui, Choo Lee Foon, and Mohd Saibani Ahmad Badruddin) for providing us with freeze-dried Asian milk samples, as well as Christophe Cavin and Thierry Delatour from the Nestlé Research Center (Lausanne, Switzerland) for their valuable collaboration.

\section{REFERENCES}

Asensio, L., I. González, T. García, and R. Martín. 2008. Determination of food authenticity by enzyme-linked immunosorbent assay (ELISA). Food Contr. 19:1-8.

Bernth Jensen, J. M., M. S. Petersen, M. Stegger, L. J. Østergaard, and B. K. Møller. 2010. Real-time relative qPCR without reference to control samples and estimation of run-specific PCR parameters from run-interval min-standard curves. PLoS ONE 5:e11723.

Buh Gasparic, M., K. Cankar, J. Zel, and K. Gruden. 2008. Comparison of real-time PCR chemistries and their suitability for detec- tion and quantification of genetically modified organisms. BMC Biotechnol. 8:26. doi:10.1186/1472-6750-8-26.

Chianese, L., P. Laezza, L. A. Smaldone, C. Stingo, L. Del Giovine, and F. Addeo. 1990. Evaluation of bovine milk in the buffalo mozzarella cheese by two-dimensional electrophoresis. Sci. Tecn. Latt. Cas. 41:315-326.

Chou, C. C., S. P. Lin, K. M. Lee, C. T. Hsu, T. W. Vickroy, and J M. Zen. 2007. Fast differentiation of meats from fifteen animal species by liquid chromatography with electrochemical detection using copper nanoparticle plated electrodes. J. Chromatogr. B Analyt. Technol. Biomed. Life Sci. 846:230-239.

Dalmasso, A., T. Civera, F. La Neve, and M. T. Bottero. 2011. Simultaneous detection of cow and buffalo milk in mozzarella cheese by real-time PCR assay. Food Chem. 124:362-366.

Fajardo, V., I. González, M. Rojas, T. García, and R. Martín. 2010. A review of current PCR-based methodologies for the authentication of meats from game animal species. Trends Food Sci. Technol. $21: 408-421$.

FAOSTAT. 2010. Food and Agricultural Organization of United Nations: Economic And Social Department: The Statistical Division. Accessed Nov. 08, 2010. http://faostat.fao.org/site/569/default. aspx\#ancor.

Ghedira, R., N. Papazova, M. Vuylsteke, T. Ruttink, I. Taverniers, and M. De Loose. 2009. Assessment of primer/template mismatch effects on real-time PCR amplification of target taxa for GMO quantification. J. Agric. Food Chem. 57:9370-9377.

ISO. 2010. ISO 17678 (IDF 202): Milk and milk products-Determination of milk fat purity by gas chromatographic analysis of triglycerides (reference method). 1st ed. International Organisation for Standardisation, Geneva, Switzerland.

Lipkin, E., A. Shalom, H. Khatib, M. Soller, and A. Friedmann. 1993 Milk as a source of deoxyribonucleic acid and as a substrate for the polymerase chain reaction. J. Dairy Sci. 76:2025-2032.

López-Calleja, I., I. González Alonso, V. Fajardo, M. A. Rodríguez, P. E. Hernández, T. García, and R. Martín. 2005. PCR detection of cow's milk in water buffalo milk and mozzarella cheese. Int. Dairy J. $15: 1122-1129$

Lopparelli, R. M., B. Cardazzo, S. Balzan, V. Giaccone, and E. Novelli. 2007. Real-time taqman polymerase chain reaction detection and quantification of cow DNA in pure water buffalo mozzarella cheese: Method validation and its application on commercial samples. J. Agric. Food Chem. 55:3429-3434.

Mafra, I., I. M. P. L. V. O. Ferreira, M. Beatriz, and P. P. Oliveira 2008. Food authentication by PCR-based methods. Eur. Food Res. Technol. 227:649-665.

Mayer, H. K. 2005. Milk species identification in cheese varieties using electrophoretic, chromatographic and PCR techniques. Int. Dairy J. 15:595-604.

Mayer, H. K., D. Heidler, and C. Rockenbauer. 1997. Determination of the percentages of cows', ewes', and goats' milk in cheese by isoelectric focusing and cation-exchange HPLC of $\gamma$ - and para-kcaseins. Int. Dairy J. 7:619-628.

Moio, L., M. L. Sasso, L. Chianese, and F. Addeo. 1990. Rapid detection of bovine milk in ovine, caprine and water buffalo milk or cheese by gel isoelectric focusing on Phastsystem. Ital. J. Food Sci. 3:185-190.

Molkentin, J. 2007. Detection of foreign fat in milk fat from different continents by triacylglycerol analysis. Eur. J. Lipid Sci. Technol. 109:505-510.

Pascoal, A., M. Prado, P. Calo, A. Cepeda, and J. Barros-Velázquez. 2005. Detection of bovine DNA in raw and heat-processed foodstuffs, commercial foods and specific risk materials by a novel specific polymerase chain reaction method. Eur. Food Res. Technol. 220:444-450.

Pirondini, A., U. Bonas, E. Maestri, G. Visioli, M. Marmiroli, and N. Marmiroli. 2010. Yield and amplificability of different DNA extraction procedures for traceability in the dairy food chain. Food Contr. 21:663-668. 
Prado, M., P. Calo-Mata, T. G. Villa, A. Cepeda, and J. BarrosVelázquez. 2007. Co-amplification and sequencing of a cytochrome $\mathrm{b}$ fragment affecting the identification of cattle in PCR-RFLP food authentication studies. Food Chem. 105:436-442.

Quinteiro, J., C. G. Sotelo, H. Rehbein, S. E. Pryde, I. Medina, R. I. Pérez-Martín, M. Rey-Mendez, and I. M. Mackie. 1998. Use of mtDNA direct polymerase chain reaction (PCR) sequencing and
PCR-restriction fragment length polymorphism methodologies in species identification of canned tuna. J. Agric. Food Chem. 46:1662-1669.

Recio, I., M. R. García-Risco, L. Amigo, E. Molina, M. Ramos, and P. J. Martín-Álvarez. 2004. Detection of milk mixtures in Halloumi cheese. J. Dairy Sci. 87:1595-1600. 